\title{
A Radio Frequency Identification (RFID) Container Tracking System for Port Louis Harbor: The Case of Mauritius
}

\author{
J. Narsoo, W. Muslun, and M. S. Sunhaloo \\ University of Technology, Mauritius
}

inarsoo@utm.intnet.mu; muslun@gmail.com; sameer.s@utm.intnet.mu

\begin{abstract} provements in air and maritime security. strategically positioned in the Indian Ocean.

Material published as part of this publication, either on-line or in print, is copy righted by the Informing Science Institute.

Permission to make digital or paper copy of part or all of these works for personal or classroom use is granted without fee provided that the copies are not made or distributed for profit or commercial advantage AND that copies 1) bear this notice in full and 2) give the full citation on the first page. It is permissible to abstract these works so long as cred it is given. To copy in all other cases or to republish or to post on a server or to redistribute to lists requires specific permission and payment of a fee. Contact Publisher@InformingScience.org to request redistribution permission.
\end{abstract}

Everyday millions of containers circle the globe and 250, 000, 000 container movements are performed around the globe yearly through 220 ports. Approximately $2 \%$ of in-transit containers are physically inspected, while empty containers are rarely inspected. A serious container event could trigger a worldwide massive port shutdown. Government security officials recognize container shipments as one of the world's greatest security threats which press for dramatic im-

Port Authorities are striving to increase efficiency through effective supply chain management, while focus is being placed on control, visibility and security. This paper is based mostly on the possible implementation of an RFID (Radio Frequency Identification) based container tracking system for Port Louis harbor. RFID will enable the identification of containers over long distances and in demanding environments such as the port area. This will help in real-time identification and tracking of containers, reaching new levels of traceability and control.

Companies will know at any point in time, where their assets are and all movements at key locations will be recorded for eventual streamlining and optimizations. These will lead to a reduced capital costs and significant overall savings in the long run for Port Louis harbor. The implementation of this system however relies on a solid collaborative network to link the various stakeholders of Port Louis harbor, by taking into considerations the specificities of Mauritius which is

SWOT Analysis and survey has been used for this study. Taking into consideration the benefits and constraints, recommendations were made as to the approach to adopt for its implementation. In the light of this research work, it was considered important to implement an RFID based solution in the port, after various RFID systems at international levels were studied and compared. The automated tracking and identification system will no doubt constitute another building block

towards achieving the vision of turning Port Louis harbor into a maritime and logistics hub in the region.

Keywords: Radio Frequency Identification, Tracking System, SWOT Analysis

\section{Introduction}

The globalization process has brought with it a number of driving forces that have caused many transformations. The 
consequences of these forces are extending to all sectors, commercial and industrial activities, including the port environment. Of these consequences, uncertainty is the one that is causing the most concern within the port industry, obliging ports to become more competitive.

As time progresses ports face increasing pressures which are represented in the different levels of competition. The increasing pressures towards the reduction of transport costs have lead container shipping companies to form shipping alliances or even go through merger and acquisition processes. Shipping companies going through these strategies are obliged to realign their trade routes.

The port industry has been viewed as a traditional, sometimes old-fashioned environment and one that reflects reactive approach to the implementation of new concepts. Being currently surrounded by an environment characterized by a high degree of complexity, where activities are often carried out in a disorganized way, with high costs, inadequate customer services and under utilization of resources, the port industry must adopt a new attitude. If not, ports may be left behind whenever alternative transport systems are designed.

It is estimated that the cost of international trade logistics, which includes all phys ical and nonphysical services and transactions required to move international trade, exceeds one thousand billion dollars per year and is growing at an annual rate of 6 to 8 per cent (Frankel, 2001). The rise in transport and logistics costs can be attributed to the growth of trade in general, and also to factors that include the increasing use of global outsourcing of manufacturing and assembly in many industries. It is often assumed that logistics costs largely comprise of transportation costs; in reality, however, the cost of transport itself frequently represents less than 50 per cent and sometimes as little as 30 per cent of total door-to-door logistics costs. The other costs include port and terminal handling charges, which are as much as sea and land transportation; and information, management and transaction cost (Frankel, 2001).

The fact that transportation costs represent a relatively small part of total door-to-door logistics costs which is particularly true with regard to container transport where larger ship sizes, double stack unit trains and other innovations. This also means that there are few opportunities to drastically lower overall logistics costs by further increasing transportation efficiencies. However, there are plenty of opportunities to improve overall logistics management through better information handling.

To become well integrated in the international supply chains, ports must ensure that they are efficient and competitive. In particular, ports must simplify administrative procedures in cooperation with customs authorities and other port stakeholders. In other words, ports and customs must implement trade facilitation measures to accelerate the handling and clearance of goods through seaports. This requires both structural reforms and the appropriate application of Information Communication Technology (ICT).

Port Louis Harbor is located in the Indian Ocean (Mauritius) on the shipping routes linking Africa, Europe, Asia and Australia. The port of Port Louis is positioned in the North-West coast of Mauritius, and is the only commercial port of the is land. It is situated at the capital city of Port Louis, which is also the administrative and economic centre point of the country. As the principal gateway of the country, the port plays a vital role by handling about $99 \%$ of the total volume of the country's external trade. Over the past two decades, the port has been transformed with modern port facilities, a dynamic Freeport, excellent port based facilities together with impressive waterfront developments. The port today, within its 300 hectares of total land area, apart from catering for port infrastructures and activities now include many port based industries, installations and Freeport related activities. Presently there are 52 port-based operators/companies and organizations within the port limits. Port Louis harbor is administered by the Mauritius Ports Authority (MPA) which is the sole national port authority in the Republic of Mauritius. As regards 
to cargo handling services, these are provided by different port operators. The main one is the Cargo Handling Corporation Ltd. (CHCL). This company operates under a concession contract with the Mauritius Ports Authority for the provision of shore handling services for containers, general cargo and certain bulk cargoes.

\section{Application of Information and Communication Technology (ICT) in the Port Sector}

Firms and industries performance and competitiveness are achieved through efficient use if ICT which provides the appropriate environment for smooth information flows and knowledge transfer. In particular, ICT has become an important tool by reducing the transaction costs involved in the production and exchange of goods and services, increasing the efficiency of management functions, and enabling firms to exchange and access more information (UNCTAD, 2003).

\section{RFID and Container Tracking in the Port}

Productivity concerns not only terminal operators but ship owners, shippers and consignees. Ensuring the most efficient loading and offloading of container ships is critical to profitability. Certainly time spent looking for containers that have not been placed where they should have been is a waste of time and in the case of perishable goods this may result in the loss of the entire shipment.

With the help of proper management software, containers can be tracked efficiently with the help of the Radio Frequency Identification (RFID) technology (Angeles, 2005; Asif \& Mandviwalla, 2005). RFID provides the ability to automatically collect real-time data without burdening employees. RFID is one of the technologies that would dramatically change the capabilities of an organization to acquire a vast array of data about the location and properties of any entity that can be physically tagged and wirelessly scanned within certain technical limitations (Chatterjee et al., 2004; We instein, 2005). This provides managers with an up-to-the-minute picture of activities and that, in turn, allows them to respond to promptly to critical situations in a timely manner. Tags can be buried at regular intervals in the passageways to serve as location markers. These tags can be read by readers in the yard and provide information on the exact location of the container and also capture the identification number of the container being transported. In spite of the potential advantages of RFID the capabilities this new technology has also engendered anxiety from certain segments of the society where concerns about personal privacy are significant (Ohkubo et al. 2005). As a result of extending the use of RFID tags to as many port applications as possible, containers with RFID container seals will enable shippers and carriers to:

- Consistently monitor container security and integrity.

- $\quad$ Speed shipments through the supply chain.

- Verify that a container was loaded at a secure loading point.

- $\quad$ Significantly reduce the like lihood a tamper event may happen during container transit.

- Gather enough data to conduct a 'virtual inspection' in advance of arrival.

- Guarantee that shipping conta iners meet governmental security regulations.

- Receive fast track or 'green lane' handling through customs at the point of dispatch and/or the point of receipt.

- $\quad$ Avoid extensive delays in the shipment and receipt.

Georgia Ports Authority (GPA), in Savannah USA, is composed of two terminals, one of which, the Garden City Terminal, is the GPA's largest and the United States' fourth-largest container terminal, with an area of 1,200 acres. Containers are shipped and received through 33 lanes spread across two gates and are moved to and from ships, trains, and trucks by 15 quay cranes. 
Containers are moved within the facility by 46 rubber-tired gantries (RTGs). The GPA is a key logistical hub in the South-eastern United States for national retailers. The GPA is expecting the container volume to rise in the next 10 years from 2 million to more than 6 million a year. The GPA is implementing an RFID-based yard automation system called ATAMS (Automated Terminal Asset Management System), developed in part by logistics and yard management software solutions provider Navis. The solution, along with other technologies, includes RFID tags and readers from IDENTEC SOLUTIONS.

Port of Singapore (PSA) has deployed thousands of RFID transponders into its container yard to create a multi-dimensional tracking grid in 1993 with the help of Texas Instruments. The PSA tracks many thousands of multi-ton cargo containers daily, and also manages arrivals and departures of up to 50 ships. PSA spent close to $\$ 910$ million in 1993 on development projects. A centralized system manages the placement and location of containers. Nowadays, the PSA is ranked the number one port worldwide.

The Port of Rotterdam is one of the largest operators of container handling systems in Holland's massive port of Rotterdam. Buried RFID transponders guide automated guided vehicles (AGVs). Deployment of this system began in 1990 using the Texas Instruments technology. The RFID automated terminals achieve a much higher efficiency than its manned counterparts. All container transfers are controlled by automated guided vehic les, and unmanned bridge cranes carry out stacking operations - all without human intervention.

The main objective of this paper has been the identification of the needs and assessing the viability for the implementation of an RFID-enabled container tracking system for Port Louis Harbor. Primary data has been collected from the major shipping lines and agencies and hence the need for the system has been assessed, where the use of information technology would be of greatest benefit and would eventually:

- $\quad$ Facilitate the flow of accurate and timely information across supply chain partners and government agencies.

- Optimize container logistics processes.

- Improve supply chain effic iency and reduce costs.

- Achieve more efficient and individual container traceability.

- Deter theft, diversion and counterfeiting.

- Integrate the RFID technology into existing business processes and gaining competitive edge for the future.

- Reduce face to face intervention, thereby reducing or eliminating opportunities for corrupt practices.

- Improve the image of Port Louis harbor.

The purpose of this paper has been to quantitatively study and evaluate the adaptability of an RFID container tracking system for Port Louis harbor in Mauritius. Furthermore, the aim is to know what can be done to use the actual strengths and opportunities of Port Louis harbor, so as to increase productivity and enhance its image as an international port. The other point is also to determine how many people and companies (who are related to container shipping and operations) are willing to put an RFID solution for better operations at Port Louis harbor.

In this paper the main research question is: Will an RFID solution be efficient for Port Louis harbor for the tracking of containers? And the follow ing five hypotheses have been considered.

1. RFID will positively influence faster container tracking and increase transparency.

2. Most port stakeholders will positively accept RFID as the future solution in two to five years. 
3. RFID will positively influence the harbor's image as an international port and more container ships will transit through Port Louis harbor.

4. RFID will positively increase efficiency and reduce costs for container tracking.

5. RFID will positively increase security at Port Louis harbor within two to five years.

\section{Data Collection Instrument}

The method for collecting primary data is through questionnaires. The interview method adopted has been quite straight forward for this survey. Approximately $20 \%$ of the respondents submit their questionnaires back through electronic mail. Personal interviews have also conducted with staff members of the Mauritius Ports Authority, Cargo Handling Corporation Limited, port stakeholders, shipping agencies, major carrier lines and other port related bodies. In practice, it is very often not possible to survey the whole population due to factors such as cost implications and time scales. However to cope with this problem a sample of the population has been considered.

The target population sampled is the staff members of the Mauritius Ports Authority, Cargo Handling Corporation Limited, port stakeholders, shipping agencies, major carrier lines and other port related bodies. A total of 52 companies are selected for the survey. However, a sample of the most concerned persons who deal with containers have been chosen, while strategic and middle management are interviewed for their views on technology forecasts and efficiency features.

\section{Limitations of the Survey}

This study has been conducted in a scientific way as far as possible, to achieve the objectives. However, there are two limitations and these are that some respondents are afraid to voice out their true opinions, since they work in government related companies and also due to time constraint.

\section{SWOT Analysis for Port Louis Harbor}

Port Louis harbor stands out by the numerous advantages it offers but also faces a number of challenges and threats. The analys is is an important step in planning and its value is often underestimated despite the simplicity in creation. The strengths, weaknesses, opportunities and threats are as follows:

\section{Strengths}

1. Mauritius is strategically located in the Indian Ocean, at the cross roads of vital trade routes linking Europe, Asia, Africa and Australia. The port is well positioned for as a hub to serve all of the Eastern and Southern regions of the African continent.

2. The port is adequately equipped in terms of infrastructure. A modern container terminal is in operation since 1999 with state of the art container handling equipment.

3. Mauritius is a stable democratic country with a strong and independent judiciary system. Owing to its long-established democratic tradition and free market economy, Mauritius is recognized internationally as a safe investment location.

4. The actual tariffs applied for trans-shipment are neither the lowest nor the highest in the region. It is therefore considered to be competitive.

5. The port offers a round the clock 7-days a week service. Ships are berthed and serviced at any time during the day or night. 
6. Industrial relations in the port are very good. No strikes can be traced for the last two decades. As such the port has not experienced any disruption of services due to unrest and uprising.

\section{Weaknesses}

1. Compared to South Africa, Mauritius is a small captive cargo base, where the premise is limited. Due to our small population size, our imports for local consumption are restricted.

2. Excessive bureaucracy and political interference in day-to-day operations are real handicaps. Although the port authority is governed by a board of directors, the chairman is a political nominee. The same situation applies for Cargo Handling Corporation Limited, the main operator.

3. Mauritius is a tropical country and is thus prone to cyclonic and other adverse weather conditions. Though the acceptable rate of downtime is 15 days, very often non-working days at Port Louis harbor exceed the above number of days.

4. Although the Mauritius Ports Authority and the Cargo Handling Corporation Limited offer a round the clock service, the other organizations, Customs and government bodies, in the port work on a $5 / 6$ day basis per week.

5. The city has been constantly growing towards the port which has constrained the expansion of the port itself.

\section{Opportunities}

1. The port of Durban which is the biggest port in the region often experiences congestion and bunching of vessels. This causes a diversion of many ships towards Port Louis harbor. Goods destined for landlocked African countries are trans-shipped at our port.

2. The adhesion of Mauritius to the various regional and international associations gives privileged access to a larger export market. China is considering this opportunity to use Mauritius as a platform to penetrate the African market.

3. The cropping up of value added industries can boost our export and contribute to an increasing mass of freight. The emergence of the seafood sector provides the opportunity for the port to become a globa1/regional leader.

\section{Threats}

1. Trans-shipment traffic is extremely volatile and dependent on the global networking strategies of a small number of shipping lines. This can disappear overnight for reasons beyond control.

2. A downturn in the Mauritian economy and/or a gradual switch towards the service industries can reduce the volume of captive cargo.

3. The emergence and development of ports of the region like Toamasina of Madagascar and Le Port of Reunion Island will no doubt increase their attractiveness. These two ports are located in the same trade route as Port Louis harbor. 


\section{Analysis and Interpretation of Data}

After the data has been collected, the same has been analyzed, using SPSS (Statistical Package for Social Sciences). However, a number of related operations have been done before the analysis has been undertaken.

\section{Results Analysis and Findings}

The results of data analysis are presented in this section for every question from the questionnaire. This is followed by an analysis of findings, using crosstabs and the interpretations of results for the survey involving the different statistical techniques. The SPSS has been used to perform the descriptive statistics and correlation analys is to test the hypotheses.

\section{Questionnaire Results}

The results of the survey are as follows:

- From the survey, most of the respondents are from import/export industries (31\%), while $28 \%$ from the container carrier industry. $17 \%$ are from government related companies, while $22 \%$ do not deal directly with the container industry as shown in Table 1 and Figure 1.

Table 1: Type of Company

\begin{tabular}{|ll|r|r|r|r|}
\hline & & Frequency & Percent & Valid Percent & Cumulative Percent \\
\hline Valid & Container Carrier & 28 & 28.0 & 28.6 & 28.6 \\
& Import/Export Agency & 31 & 31.0 & 31.6 & 60.2 \\
& Government Related & 17 & 17.0 & 17.3 & 77.6 \\
& Others & 22 & 22.0 & 22.4 & 100.0 \\
& Total & 98 & 98.0 & 100.0 & \\
Missing & System & 2 & 2.0 & & \\
Total & & 100 & 100.0 & & \\
\hline
\end{tabular}

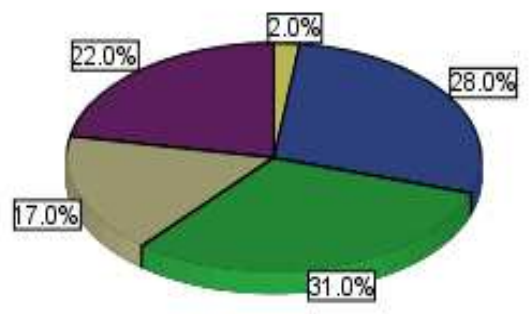


- $33 \%$ of the respondents work in companies who have between 0 and 99 staff members, while the majority works in companies where the number of staff is between 100 and 499. $25 \%$ work in companies having more than 500 persons.

- $43 \%$ of respondents are from middle management, $29 \%$ from operations management, $21 \%$ from strategic management, while $5 \%$ are not in a decision making position.

- $39 \%$ of the sampled population is not satisfied with the present level of service and quality of information of Port-Louis harbor. $24 \%$ find the service good, $21 \%$ are very satisfied, $9 \%$ find it bad presently and $5 \%$ are not satisfied at all.

- $50 \%$ of the respondents have at least once experienced container delays, while $48 \%$ have never had that problem previously.

- Only $25 \%$ of the sampled population has experienced any kind of container breach or theft, while a majority of $75 \%$ never has this problem.

- $80 \%$ of the respondents are interested in emerging technologies and only $18 \%$ are not interested.

- $33 \%$ of respondents have only heard about the RFID technology, while only $16 \%$ have a good knowledge of it. $24 \%$ do not know about the RFID technology.

- $28 \%$ of the respondents think that RFID can be used in the "transports/logistics for tracking and tracing", $26 \%$ believes that it forms part of a "supply chain processes", $16 \%$ says that it is used mainly in the "production control environment", $15 \%$ think it integrates with "asset management for warehouses" and 13\% opts for other industries.

- $27 \%$ of the respondents find that RFID will enhance information accuracy and transparency and improve customer service. 17\% stress on the security aspect of RFID, $14 \%$ opt for efficiency of processes and $13 \%$ say that it will reduce costs.

- $72 \%$ say that RFID will improve productivity in Port Louis harbor.

- $90 \%$ of respondents think that RFID will generally reduce container tracking time.

- $81 \%$ of respondents said that RFID will enhance security, while only $17 \%$ thinks otherwise.

- $68 \%$ of the surveyed population agrees that RFID implementation has associated problems with it, while only $30 \%$ disagrees.

- $24 \%$ of respondents find that RFID will increase unemployment, $21 \%$ relate the problem to massive technological investments, $12 \%$ to other issues, $11 \%$ to telecommunication and legal issues and 30\% have no idea about the associated problem.

- $28 \%$ of respondents say that because of insufficient funding, RFID have not yet been implemented in Port Louis harbor. 27\% think that the government is not interested in the technology, 24\% say that it is because of the lack of knowledge about the system and $27 \%$ say that it is because of the uncertainties about the mandates and adopted standards.

- $50 \%$ agree that RFID will be implemented in Port Louis within 2-5 years, 38\% say that it will be more than 5 years, $8 \%$ say that it will be implemented within 2 years and $2 \%$ disagree with the statement.

The analysis and hypotheses is presented in the next section. 


\section{Hypothesis 1: RFID will Positively Influence Faster Container Tracking and Increase Transparency}

From Table 2, 21\% from the sample is "Verify Satisfied" with actual level of service and 24\% have a "Good" opinion of the actual service. This adds up to $45 \%$ of sample having a good experience with the actual service. From these $45 \%, 36 \%$ believe that an RFID system for container tracking can reduce time for container spotting and delivery. From the survey we denote a 53\% non-satisfaction with actual level of service and this further confirms their non-satisfaction where $94 \%$ of them say that an RFID system for container tracking can reduce time for container spotting and delivery.

Table 2: Reduction in time for container tracking, Satisfaction and quality of information

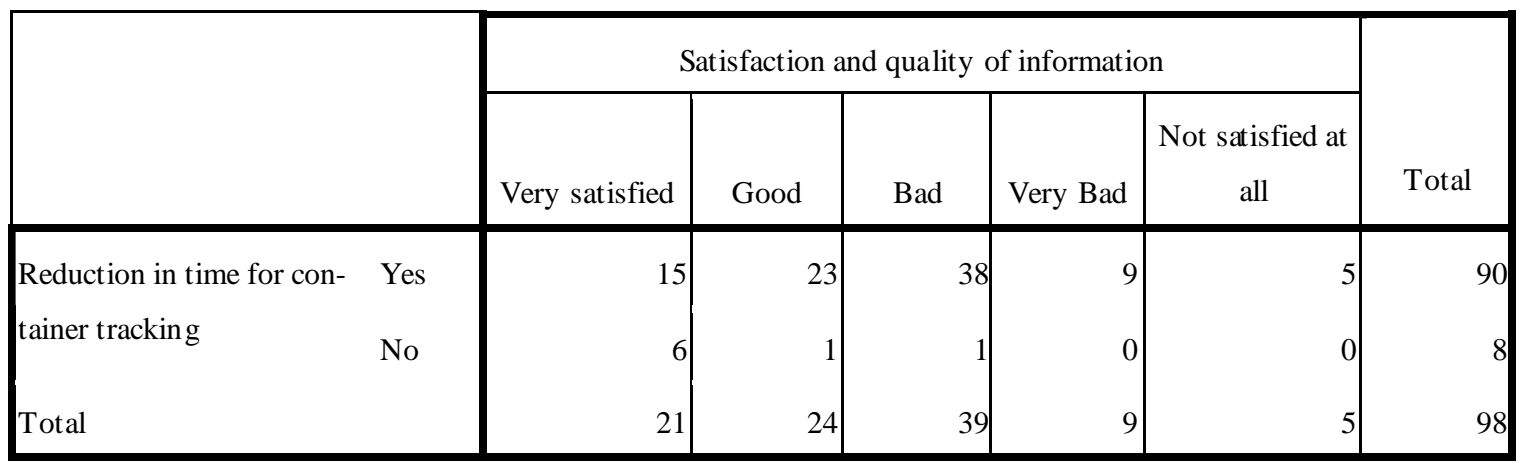

Table 3: Re duction in time for container tracking - Container de lays

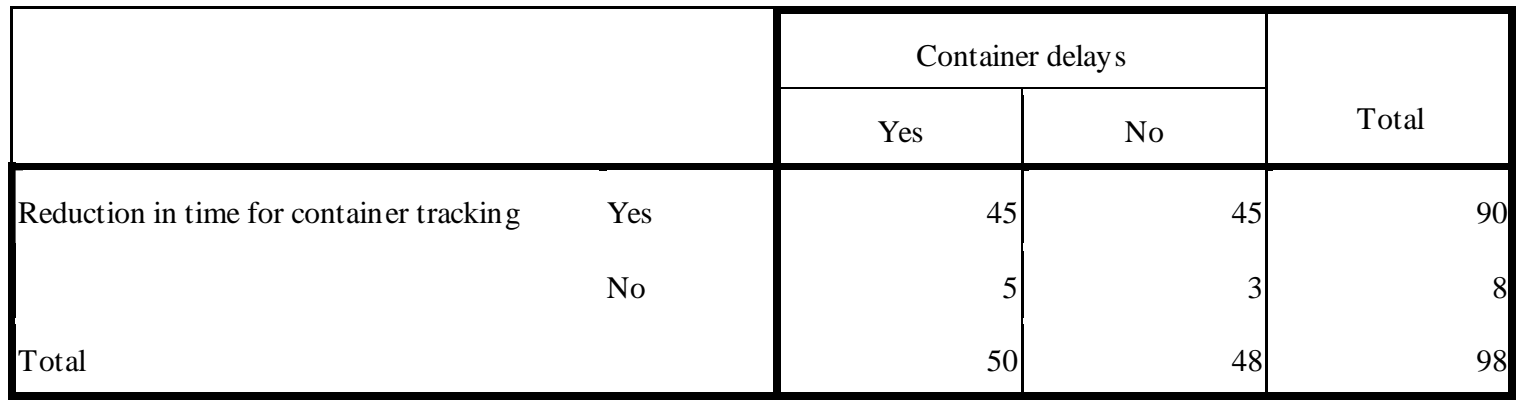

The survey reveals that $48 \%$ from the sample have never experienced delays in receiving their container. However, though having a good experience most of them are of opinion that RFID will bring reduction in time for container tracking.

Table 4: Reduction in time for container tracking - Container security

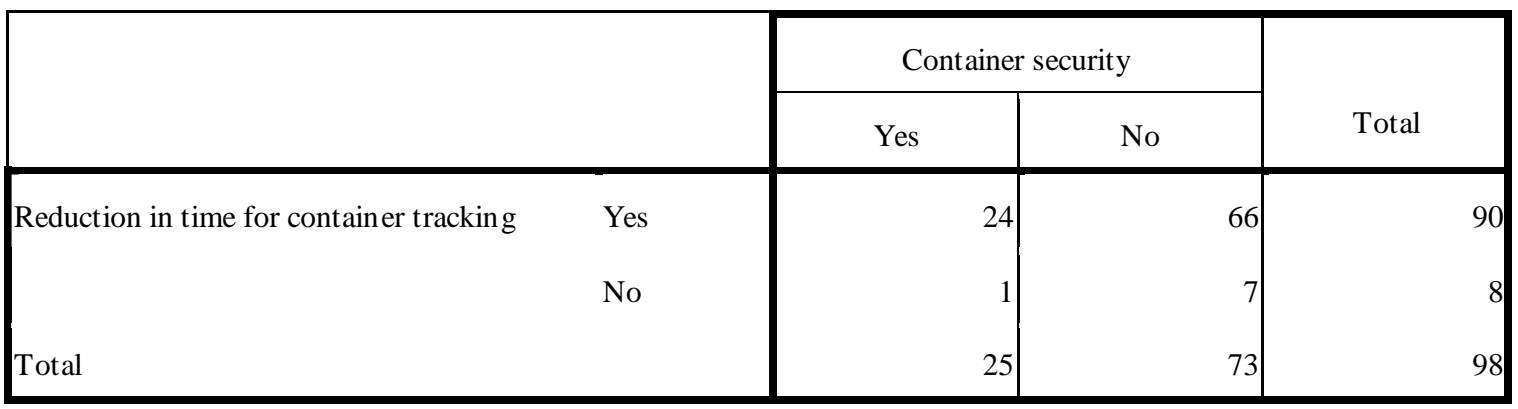


From Table 4,73\% of the sample has not encountered a problem of lost or tampered container. From these $73 \%$ respondents, $62 \%$ believe that RFID will bring reduction in time for container tracking.

Table 5: Chi-square test for reduction in time for container s potting and le vel of satisfaction

\begin{tabular}{|c|c|c|c|}
\hline & Value & df & Asymp. Sig. (2-sided) \\
\hline Pearson Chi-Square & 15.053 & 4 & .005 \\
\hline Likelihood Ratio & 12.674 & 4 & .013 \\
\hline Linear-by-Linear Association & 9.685 & 1 & .002 \\
\hline $\mathrm{N}$ of Valid Cases & 98 & & \\
\hline
\end{tabular}

a. $\quad 6$ cells $(60.0 \%)$ have expected count less than 5 . The minimum expected count is .41 .

Testing at 5\% significance level, the Pearson's Chi Square value generated is 15.053 while the P value is 0.005 , which is lesser than 0.05 as shown in Table 5. This implies that there is an association between Reduction in time for container tracking and container delays. In order to check the strength of the association, the Cramer's V, Phi value is used. From Table 6, the Phi and Cramer's V values are 0.392, meaning there is an association between the two. Additional testing is carried out in the form of Correlation Analys is and using the Spearman's Rho, to establish the relationship between reduction in time for container spotting and level of satisfaction of port stakeholders.

Table 6: Symmetric measures for reduction in time for containe r spotting and level of satis faction

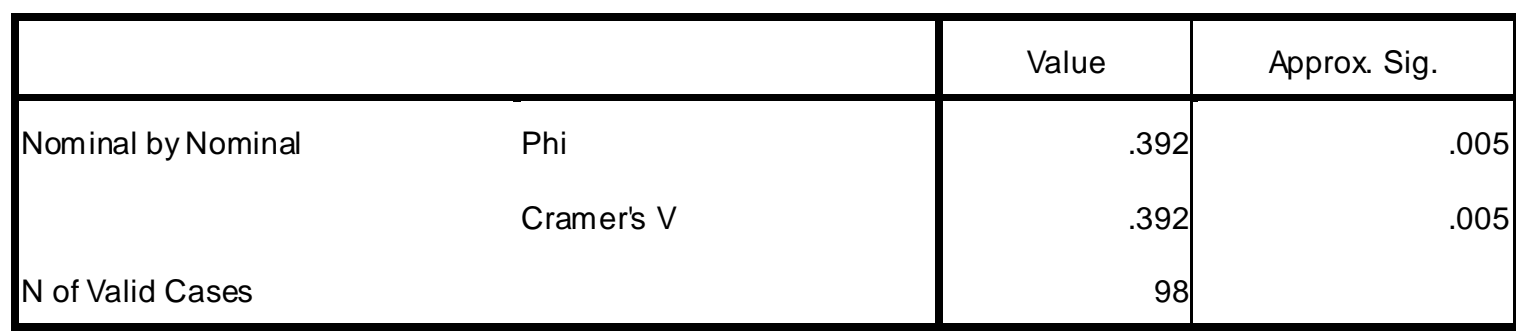

As shown in Table 7, there is a signif icant correlation of -0.319 between Satisfaction and quality of information and Reduction in time for container tracking. The significance value is 0.01 and is less than 0.05 , meaning that there is a significant relationship between the two variables. 
Table 7: Spearman's rho coefficients for reduction in time for container spotting and level of satis faction

\begin{tabular}{|lll|r|r|}
\hline & & $\begin{array}{l}\text { Satisfaction and } \\
\text { quality of infor- } \\
\text { mation }\end{array}$ & $\begin{array}{c}\text { Reduction in } \\
\text { time for con- } \\
\text { tainer tracking }\end{array}$ \\
\hline $\begin{array}{l}\text { Spearman's } \\
\text { rho }\end{array}$ & $\begin{array}{l}\text { Satisfaction and quality of } \\
\text { information }\end{array}$ & Correlation Coefficient \\
& Sig. (2-tailed) & 1.000 & $-.319^{*}$ \\
& $\mathrm{~N}$ & 98 & .001 \\
& $\begin{array}{l}\text { Reduction in time for con- } \\
\text { tainer tracking }\end{array}$ & Correlation Coefficient & $-.319^{* *}$ & 98 \\
& Sig. (2-tailed) & .001 & 1.000 \\
& $\mathrm{~N}$ & 98 & 98 \\
\hline
\end{tabular}

${ }^{* *}$. Correlation is significant at the 0.01 level (2-tailed).

The introduction of RFID will reduce time for container tracking as confirmed by the above tests and cross tabs. The possible reason for such keen interest about RFID could be the idea of using new and enhancement in technology. Those respondents that do have some knowledge about RFID and its application in the supply chain sector have added positive ly to this conclusion. The adoption of more sophisticated techniques has proved its viability over various industries. To conclude, the introduction of an RFID is seen to be a new turning in the port sector.

\section{Hypothesis 2: Most Port Stakeholders Will Positively Accept RFID as the Future Solution in Two to Five Years}

More than 50\% of the respondents insist that RFID will be applicable in Logistic and Supply Chain and $18 \%$ are from Import/Export Agency. The survey revealed that $43 \%$ are from Middle Management and 26\% have at least some knowledge of RFID. It is also noted that less than $25 \%$ do not have know ledge of RFID.

The relationship between types of problem in the harbor and the factors preventing the implementation of RFID reveals that $21 \%$ opinion that problems associated with RFID will exist and from the same $21 \%$ respondents more than $50 \%$ say that non-availability may have been the reason for non-implementation of RFID.

The Pearson's Chi Square value generated is 32.270 while the $\mathrm{P}$ value is 0.001 . This implies that there is an association between the types of problems for RFID and why RFID has not yet implemented in Port Louis harbor. The strength of the association is clarified using the Cramer's V, Phi values. The Phi and Cramer's V values are 0.574 and .331, meaning there is an association between the two variables.

There is a significant correlation of -0.119 between Types of problems for RFID and RFID not yet implemented in Port Louis harbor. The significance value is 0.024 meaning that there is a relationship between the two variables.

The introduction of an RFID in the port sector will definitely request the opinion of its stakeholders. Most of the stakeholders from the sample size have positively indicated their opinion. It is therefore worth pointing out that mostly middle management, from container carriers and im- 
port/export agencies, is interested in the technology, since they have a sound knowledge of RFID. Middle management will normally put ideas forward in most companies so as to guide senior management in decision making. A significant number of respondents thinks that RFID will increase unemployment in the port sector, but this is a debatable issue since there will always be staff needed to monitor any system. As analyzed and proved, the acceptance of an RFID shall be well viewed as a future solution to the actual port operations.

\section{Hypothesis 3: RFID will Positively Influence the Harbor's Image as an International Port and More Container Ships will Transit through Port Louis Harbor}

$72 \%$ of the respondents are agreeable to the statement "will an RFID positively influence the harbor's image as an international port and more container ships will transit through Port Louis harbor". Nearly $60 \%$ of those not having experienced on de lays are agreeable to the statement as well. This analys is proves that the RFID will certainly bring enhanced benefit to the port sector and its operators.

The cross relationship between the opinion of respondents on the possible reduction in time for container tracking and whether the respondent have ever experience tampered container is considered. Out of those who have never experienced tampered container problem, $66 \%$ of them believe that RFID will bring a reduction in time for container tracking. From this analys is we can confirm that an RFID system will surely bring a boost to the image of the actual harbor.

The Pearson's Chi Square value is 8.223 while the $\mathrm{P}$ value is 0.004 . This implies that there is an association between RFID for improved productivity in Port Louis harbor and container delays. The Phi and Cramer's V values are 0.290, meaning there is an association between the two variables. The results also indicate that there is a significant correlation of 0.290 between container delays and RFID for improved productivity in Port Louis harbor.

Despite the fact that some companies do not complaint about container delays and container security, they still find it necessary that Port Louis harbor should implement an RFID system. This will definitely reduce the time taken for tracking and tracing containers, hence optimizing on port operations. Most of the stakeholders from the sample size have again positively indicated their opinion and this clearly shows that in implementing an RFID container tracking system, the port will have its image boosted internationally and many container carriers will have trust in the system since RFID is well known for its visibility and control aspects. Any traces of corruption in the supply chain can hence be detected and unveiled.

\section{Hypothesis 4: RFID will Positively Increase Efficiency and Reduce Costs for Container Tracking}

$28 \%$ of the operators have indicated that RFID will be of great use in Transport/Logistics for tracking and tracing industry. This implies that with the different features and characteristics of the RFID, it will surely bring effic iency and cost reduction at certain operational level. A cross analys is, of those who have said that RFID will be applicable to Transport/Logistic Industry, shows that the benefits of RFID will be in terms of efficiency and cost reduction. Out of the $28 \%$ respondents, $16 \%$ have opted for efficiency and $7 \%$ have opted for cost reduction.

Most of the respondents believe that an RFID will improve productivity in the Port Louis harbor, where $72 \%$ have given this view. A parallel comparison and assumption indicates that respondents believe in the easy flow of container tracking and thus saving time to further reduce associated costs. $68 \%$ have said that there will be a reduction in time. We also note that $22 \%$ having a 
Nars oo, Muslun, \& Sunhaloo

negative opinion on productivity aspect of RFID, have said that an RFID will bring time reduction.

\section{Hypothesis 5: RFID will Positively Increase Security at Port Louis Harbor within Two to Five Years}

$81 \%$ from the population sampled believe that RFID will bring an enhancement to the security factor at the Port Louis harbor. Out of those $81 \%, 14 \%$ also agree that the implementation of RFID will benefit to all operators in terms of security. Out of $81 \%$ respondents, $49 \%$ also say that RFID will be implemented within 2 to 5 years, $24 \%$ say that it will be implemented after 5 years. Though not believing in the security aspect of an RFID, out of $17 \%$ respondents nearly all view that an RFID container tracking system could be implemented after 5 years.

The Pearson's Chi Square value is 29.495. This implies that there is an association between enhancement of security by RFID in Port Louis harbor and the time that this implementation will take place. The Phi and Cramer's V values are 0.549 , meaning there is an association between the two variables. Additional testing in the form of Correlation Analysis is performed using the Spearman's Rho, to establish the relationship between container delays and improvement of security. There is a correlation of 0.500 between security enhancement in Port Louis harbor and when it will be implemented. The significance value is far less than 0.05 , meaning that there is a significant relationship between the two tested variables.

As pointed out by the above results, RFID will ultimately enhance security in the port. Due to globalization, more and more ports and container carrier agencies will implement RFID as the de facto standard for the logistics supply chain, using. Terrorist attacks, container tampering and container losses have possibly encouraged respondents to rethink about the security strategy that is currently being offered in Port Louis harbor.

\section{Justification of an RFID Container Tracking System for Port Louis Harbor}

Recent developments in the sphere of international trade have increased the need for tightened security and to increase efficiency and visibility. The dual missions of protecting a country and collecting duties and taxes drive governments' interest in maintaining the integrity of the supply chain. The interest of private companies in just-in-time, reliable delivery, cost effective logistics, and maintaining the integrity of goods leads to the development of many tracking systems.

The main reasons for the implementation of an RFID container tracking system arise from the need that a lot of containers are misplaced, tampered with at other ports, lost in transit and due to international security measures for competitiveness.

The Information and Communications Technology (ICT) sector has witnessed remarkable progress over the past last years and the ambition of the Government is to transform Mauritius into a Cyber Island. The vision of Government is to make ICT the fifth pillar of our economy. The Cyber City is expanding to house business parks, telecentres and teleports and also to provide office facilities for those who intend to offer information technology services in Mauritius. The is land is also positioning itself to offer services such as back-office operations, payroll and marketing support services on an international basis.

Within such a perspective, it is quite natural that the only port of the country contributes in promoting the image of Mauritius. Leading companies in the port sector already have their own internal IT systems. An RFID system will enable for a proper maritime container information system in the supply chain with all actors of the port sector. This will allow for more visibility and 
control of operations, hence making Mauritius more competitive compared to other ports in the African region.

At company level, the establishment of an RFID system would spare the effort and resources required for the re-input of data. Information entered in one port can be tracked and updated at any port hence this will inevitably lead to a lower cost in providing services to customers. Security will be enhanced in the port due to real-time scanning and containers that have not been tampered can be processed in a fast track mode, whereby increasing the productivity of the port. Shipping agents can constantly monitor their container activities by using a combination of RFID and GPS technology through a web interface. There will be no need for them to dispatch agents for this exercise.

On the other hand the government is striving hard to maintain the competitiveness of the sugar sector and the clothing and textile industry in Mauritius. Lowering of cost is being envisaged through centralization and mechanization. A decrease in the cost of exportation of our products will no doubt enhance the competitiveness of our products in the international markets.

The RFID container tracking solution can be further enhanced by linking all the port stakeholders in the supply chain, using a proper information system. This will undoubtedly facilitate the easy delivery of cargo, resulting in unnecessary delays, with an accurate and timely flow of information.

Efforts to improve the security of the container shipping system continue to be focused on ports and facilities. Unfortunately, the route over which cargo travels is vast and difficult to secure. Security efforts should address vulnerabilities along supply-chain network edges so as to keep cargo secure while it is en route, hence moving along for a comprehensive strategy to secure the global container supply chain. The RFID technology can be further enhanced to detect weapons or illegal shipments by offering remote scanning of explosives and radiation detection to improve the security of the container shipping system in Port Louis harbor.

Tracking offers benefits to both private and public sector individuals, allowing for real-time visibility of goods and the ability to receive advanced information regarding cargo and security status. The primary means of tracking cargo, through RFID and GPS technologies, are quite common yet still require further development to truly provide accurate and secure information with regard to the location and status of containers.

The private sector will be responsible for triggering the development and enhancement of technologies which further expand current container tracking capabilities. The Mauritian government can provide incentives to companies developing tracking alternatives, or mandating the use of certain technologies on all cargo/container shipments. As they progress, more quantif iable information will be available, allow ing for countries and companies to make more informed decisions regarding cargo and vehicle tracking and the associated technologies.

While there is currently no mandate for RFID in any of the current regulations, there is every indication that it will be recognized within a few years as a means of compliance.

\section{Conclusion}

Over the years, heavy investments have been made in port infrastructure to transform Port Louis from a labor intensive archaic port into what it is today with deep water quays and state of the art cargo handling equipment. To realize its vision and ambition and to become a regional hub in this part of the Indian Ocean, dredge works were recently carried out to enable accommodation and handling of fifth generation container vessels with drafts of up to 13 meters. With the completion of dredging works to a water depth of 14.5 meters below chart datum, Port Louis is now the second container port in the Sub-Saharan Africa with an accommodation channel of such 
depth. The construction and operation of larger vessels have been motivated by the gains from economy of scale.

Throughout the evolution of maritime transports, there has been a continuous attempt to harmonize all the different elements, be it operational, documentary or terminology to enable those operating in the trade to better understand each other. Until recently, the most common problem related to containers is the gap between the date when information was gathered and when it was loaded into a database. The system relied heavily on manually gathering of information.

Following certain events like the terrorist attack of September 11 and new exigencies of the majority of ports, it has been deemed necessary to include all those who have an interest, controlling responsibility and liability for cargo to be involved in a process not to only provide information as to the whereabouts of the cargo, but also to be in conformity with the exigencies of new legislations mainly in Europe and USA for the prevention of importation of cargo of mass destruction on their soils. Whatever could be the level of conformity w ith worldwide exigencies, it is becoming imperative that the basic requirements of the World Customs Organization (WCO) frameworks.

It is important to point out that Mauritius is not the only country to be strategically positioned in the region. We have two main competitors: Reunion Island and Madagascar. The latter is becoming a bigger threat to us namely because they have a low cost of living, and available cheap labor. Previously it was not of direct threat to Mauritius because of political instability prevailing.

With this threat in mind, Mauritius should wait no longer to modernize its port by implementing an appropriate RFID container tracking system. The latter will not only encourage transparency and accountability but will also provide an effective and efficient single point data system. Transparent transactions of containers by our local importers and exporters will also eventually place the country as being compliant with new security measures that could encourage the consolidation of Port Louis as the regional hub. No doubt, such effort would go waste in the absence of a proper network for the distribution of the information to all stakeholders.

Image plays a key role in the life of a business and is a critical issue worthy of serious attention. The way a business is perceived by its customers, competitors, prospects, the general public, the government and the press has a profound effect on the success of the enterprise. Even the reason why one company can charge higher prices than a comparable firm may have more to do with image than anything else. As Mauritius has embarked on the development of a seafood hub, where the port will be called to play a crucial role, there is a need to project the image of Port Louis as a modern and efficient port.

Having said all that, nothing will be achieved if no parallel measures are implemented. First of all, the problem of traffic congestion in Port Louis needs to be addressed. It will be of no avail to optimize on container movements through RFID, while it takes lot of time through road traffic to access and exit the port. Secondly and most importantly, Mauritius needs to have political will and courage to implement unpopular measures that will in the long term benefit its economy. The implementation of an RFID solution will no doubt provide the required collaborative network that would facilitate the flow of accurate and timely information across supply chain partners and government agencies, reducing face to face intervention, opportunities for corrupt practices and provide an improved service to port customers and users by reducing turnaround time of ships and dwell-time of cargo in port. 


\section{References}

Angeles, R. (2005). RFID technologies: Supply-chain applications and implementation issues. Information Systems Management, 22(1), 51-65.

Asif, F., \& Mandviwalla, M. (2005). Integrating the supply chain with RFID: A technical and business analysis. Communications of the Association for Information Systems, 15(24), 393-426.

Chatterjee, R., Wolfe, P., Park, S., \& Choi, J. (2004). Evaluation of using passive RFID tags for monitoring product location / ownership. In Proceedings of the 2004 IIE Annual Conference, Houston, TX.

Frankel, E. (2001). The e-port terminal operations in the Internet age: Information and transaction management as a key to profitability for shipping and ports. (unpublished paper).

Ohkubo, M., Suzuki, K., \& Kinoshita, S. (2005). RFID privacy issues and technical challenges. Communications of the ACM, 48(9). 66-71.

UNCTA D. United Nations Conference on Trade and Development. (2003). Report by the UNCTAD secretariat on E-commerce and Development 2003, Internet Edition prepared by UNCTAD Secretariat, Complete Version, Overview pp. xvii.

Weinstein, R. (2005). RFID: A technical overv iew and its application to the enterprise. IT Professional, 7(3), 27-33.

\section{Biographies}

J. Narsoo is a Lecturer at the University of Technology Mauritius.

W. Muslun was a postgraduate student at the University of Technology Mauritius.

M.S. Sunhaloo is a Senior Lecturer at the University of Technology Mauritius. 